\title{
PEMBINAAN EKSTRAKURIKULER HIZBUL WATHAN SEBAGAI WAHANA PENINGKATAN KOMPETENSI BELA NEGARA PESERTA DIDIK
}

\author{
Endang Listiowaty \\ Fakultas Ilmu-Ilmu Kesehatan Universitas Muhammadiyah Prof. Dr. Hamka (Uhamka) \\ listiowatyendang@gmail.com
}

\section{ABSTRACT}

The purpose of this study was to describe the extracurricular development of Hizbul Wathan (HW) as a vehicle for improving students' state defense. The research uses a qualitative approach. Research locations in three schools. The subjects of this research are the coaches and students. Data collection was carried out from July to December 2020, using observation, interview, and documentation techniques. To ensure the validity of the data, data triangulation was carried out.

Research result. First, the extracurricular activities of $H W$ invite all elements of the nation to unite, establish ukhuwah Islamiyah and Wathaniyah, as well as mutual cooperation and respect for each other. Second, in terms of activity, it still needs to be improved. In SMA M 12 about 50\% are active. In SMA M 14 around 50\%. Furthermore, in SMK M 12, 65\% are active. Third, HW activities have a solid foundation for improving the quality of students, especially in strengthening Islamic beliefs and love for Muhammadiyah. Finally, fourth, a number of obstacles were found in improving the competence of defending the state.

Keywords: Extracurricular, Hizbul Wathan, State Defense Competence, Students

\section{ABSTRAK}

Tujuan Penelitian ini adalah untuk mendeskripsikan pembinaan ekstrakurikuler Hizbul Wathan $(H W)$ sebagai wahana peningkatan bela negara peserta didik. Penelitian menggunakan pendekatan kualitatif. Lokasi penelitian di tiga sekolah. Subjek penelitian ini adalah pembina dan peserta didik. Pengumpulan data dilakukan pada bulan Juli sampai dengan Desember 2020, dengan menggunakan teknik observasi, wawancara, dan dokumentasi. Untuk meyakini keabsahan data dilakukan triangulasi data.

Hasil penelitian. Pertama, kegiatan Ekstrakurikuler HW mengajak seluruh elemen bangsa bersatu, menjalin ukhuwah Islamiyah dan Wathaniyah, serta gotong royong dan menghormati antar sesama. Kedua, dari sisi keaktifan masih perlu ditingkatkan. Di SMA M 12 sekitar 50\% yang aktif. Di SMA M 14 sekitar 50\%. Selanjutnya di SMK M 12, $65 \%$ yang aktif. Ketiga, kegiatan HW mempunyai landasan yang kokoh bagi peningkatan kualitas peserta didik, terutama dalam pemantapan keyakinan keIslaman dan kecintaan pada oMuhammadiyah. Terakhir, keempat, ditemukan sejumlah kendala dalam peningkatan kompetensi bela negara.

Kata Kunci: Ekstrakurikuler, Hizbul Wathan, Kompetensi Bela Negara, Peserta Didik

\section{PENDAHULUAN}

Hizbul Wathan (HW) berarti "Pembela Tanah Air". HW adalah sebutan Kepanduan sebagai salah satu organisasi otonom di Muhammadiyah. Anggotanya laki-laki maupun perempuan. Organisasi ini juga merupakan forum bagi Muhammadiyah dalam menyebarkan dakwahnya dengan tujuan amar ma'ruf nahi munkar. Organisasi HW digunakan sebagai kegiatan ekstrakurikuler di sekolahsekolah Muhammadiyah, mulai dari tingkat Sekolah Dasar sampai tingkat Perguruan Tinggi. 
Kegiatan Kepanduan Hizbul Wathan merupakan pembinaan yang bersifat non formal, dilaksanakan di lingkungan keluarga, lingkungan pendidikan, dan masyarakat. Kegiatan organisasi ini memiliki banyak manfaat selain sebagai fasilitas dakwah Muhammadiyah, juga merupakan pembinaan yang memenuhi kebutuhan pada segmennya yang selama ini tidak dioperasikan oleh institusi lain. Pelaksanaannya menggunakan perinsip dasar Kepanduan dan metode Kepanduan serta memiliki ciri dan jati diri Kepanduan di alam terbuka (Kegiatan luar ruangan) serta upaya pendidikan mandiri bagi para anggotanya.

Sebagaimana nama Hizbul Wathan yang berarti cinta tanah air, kurikulum ekstrakurikuler HW seharusnya melingkupi kompetensi bela negara. Mencintai tanah air berarti menjaga, membela, dan mempertahankan negara terhadap ancaman baik dari dalam maupun dari luar. Bela Negara adalah sikap dan perilaku warga negara yang dijiwai oleh kecintaannya kepada Negara Kesatuan Republik Indonesia yang berdasarkan Pancasila dan UndangUndang Dasar 1945 dalam menjalin kelangsungan hidup bangsa dan negara yang seutuhnya.

Peserta didik harus belajar giat demi membela negara agar memiliki mental positif, karena bangsa yang bermental positif melahirkan bangsa yang kuat, berprestasi tinggi yang berdampak pada segannya pihak pihak luar untuk mengintervensi suatu bangsa. Upaya bela negara tidak hanya upaya memanggul senjata. Mematuhi semua tata tertib sekolah dengan tertib, mengikuti kegiatan belajar dan mengajar dan upacara dengan baik, menjaga nama baik sekolah, baik itu di dalam sekolah maupun lingkungan masyarakat juga merupakan sikap dari bela negara.

Undang-Undang Dasar Negara Republik Indonesia Tahun 1945 (UUD 1945) mengatur mengenai Upaya Bela Negara yaitu ketentuan Pasal 27 Ayat (3): "Setiap warga negara berhak dan wajib ikut serta dalam upaya pembelaan Negara," dan Pasal 30 Ayat (1): “Tiap- tiap warga negara berhak dan wajib ikut serta dalam usaha pertahanan dan keamanan negara." Upaya bela negara harus dilakukan dalam kerangka pembinaan kesadaran bela negara sebagai sebuah upaya untuk mewujudkan WNI yang memahami dan menghayati serta yakin untuk menunaikan hak dan kewajibannya. Berkaitan dengan itu, peneliti tertarik meneliti bagaimana pembinaan ekstrakurikuler Hizbul wathan sebagai wahana peningkatan kompetensi bela negara peserta didik.

\section{KAJIAN LITERATUR}

\section{Bela Negara}

Suwarno Widodo (2011) menjelaskan bahwa bela Negara adalah sikap dan tindakan warga Negara yang dilandasi rasa cinta tanah air, kesadaran berbangsa dan bernegara, keyakinan pancasila sebagai ideology bansa dan Negara, kerelaan berkorban guna menghadapi setiap ancaman, tantangan, hambatan dan gangguan (ATHG) baik yang datang dari Negara, keutuhan wilayah, yridiksi nasional dan nilainilai luhur Pancasila dan Undang-Undang Dasar 1945. Kader-kader bangsa inilah yang nantinya akan menjadi ujung tombak dalam memperjuangakan tetap tegak dan eksisnya Negara Kesatuan Republik Indonesia dalam percaturan masyarakat global. Mereka membela Negara dalam menghadapi problem ideology, politik, ekonomi, sosbud dan hankam. Untuk bisa melahirkan kaderkader tersebut harus dirancang serta sistematis dan berkelanjutan. Relevansi dari jurnal ini untuk dijadikan sebagai rujukan karena sama-sama membahas tentang Bela Negara yang diterapkan terhadap peserta didik. Bela Negara dapat dilakukan kapan saja di mana saja.

\section{Hizbul Wathan dan bela negara}

Gerakan Kepanduan Hizbul Wathan merupakan salah satu organisasi Muhammadiyah yang dibangkitkan kembali pada tahun 1999. Peran Hizbul Wathan banyak terlihat pada sektor penanaman semangat Cinta Tanah Air, dan itu sudah dimulai sebelum Indonesia merdeka. Sesuai dengan makna Hizbul 
Wathan yang berarti cinta tanah air, tujuan utamanya adalah mendidik pemuda Muhammadiyah pada waktu untuk menjadi pejuang yang siap membela tanah air. Sehingga nilai-nilai cinta tanah air adalah nilai yang harus dipegang teguh HW untuk membela Negara bersama aparatur Negara jika ada pihak luar yang mengganggu kedaulatan Negara Kesatuan Republik Indonesia. Cinta dan Bela Tanah Air. Tanah air sebagai tempat lahir, hidup dan matinya seseorang mulai dikenal dan mengental dalam sejarah manusia seiring dengan lahirnya konsep bangsa-negara (Nationstate) pada awal abad ke-19 hingga memunculkan nasionalisme yang berakar dari etnosentrisme ( Suara Muhammadiyah, edisi 22, Tahun 2017.)

Dalam pandangan para aktifis Hizbul Wathan, bela Negara artinya suatu tindakan yang dilakukan dalam rangka menjaga dan mempertahankan keutuhan suatu bangsa (Negara). Upaya bela Negara tidak harus dilakukan oleh angkatan bersenjata seperti TNI dan Polri saja. Sebagai warga Negara yang baik, sudah menjadi kewajiban bagi seluruh masyarakat Indonesia untuk ikut serta dalam membela Negara. Hal ini sesuai dengan bunyi Undang-Undang RI Nomor 3 Tahun 2002 Pasal 9 ayat (1) Tentang Pertahanan Negara yang mengamanatkan bahwa setiap warga Negara berhak dan wajib ikut serta dalam upaya bela Negara yang diwujudkan dalam penyelenggaraan pertahanan Negara.

Supriyadi (2018) menyatakan bahwa melalui pendidikan, nilai-nilai yang telah diajarkan dikembangkan untuk membangun kemampuan diri dalam olah pikir, olah hati, olah rasa dan karsa serta olah raga, baik secara individual maupun kolektif. Sejak awal kelahirannya, pendidikan kepanduan, khususnya kepanduan Hizbul Wathan telah melakukan penanaman nilai-nilai kebangsaan, yakni sebagai gerakan pembela Tanah Air. Gerakan ini berazaskan Islam, untuk menyiapkan dan membina anak, remaja, dan pemuda menjadi manusia Muslim yang sebenarbenarnya dan siap menjadi kader persyarikatan, umat, dan bangsa. Program-program pendidikannya melibatkan pengembangan potensi kejiwaan individu dan mengaitkannya dengan aspek social kebudayaan. Gerakan Kepanduan Hizbul Wathan juga menetapkan kriteria persyaratan dalam setiap kenaikan jenjang. Kriteria-kritera itu menunjukkan pendidikan capaian pendidikan karakter individu dan karakter public, termasuk di dalamnya adalah karakter bangsa.

\section{METODOLOGI PENELITIAN}

Penelitian ini menggunakan pendekatan kualitatif. Metode yang dipilih adalah metode deskriptif yang digunakan untuk mendeskripsikan secara terperinci fenomena sosial tertentu (Suradika, 2000: 13). Data dikumpulkan dengan teknik wawancara, observasi, dan dokumentasi. Informan dalam penelitian ini dipilih dengan teknik purposive sebanyak 25 orang. Data dianalis dengan mengikuti langkah-langkah yang disarankan Miles dan Huberman sebagaimana dikutip Sanapiah (1999: 256), yaitu pengumpulan data, reduksi data, pengambilan kesimpulan, dan display data.

\section{HASIL DAN PEMBAHASAN}

Temuan di lapangan di ketiga sekolah yang menjadi lokus penelitian dapat disajikan ke dalam display berupa tebel aktifita HW di tiga sekolah dimaksud berikut ini:

\section{Tabel 1Hasil Penelitan Lapangan}

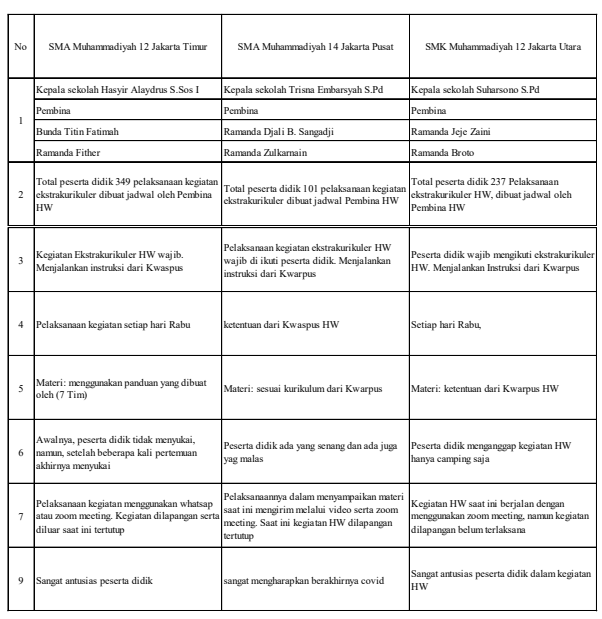

5. KESIMPULAN 
Dalam pembinaan ekstrakulikuler Hizbul Wathan di SMA/SMK Muhammadiyah DKI Jakarta. Pembina menyampaikan materi yang dapat diterima oleh peserta didik sesuai dengan kurikulum yang telah ditetapkan Kwarpus HW. Dengan adanya kurikulum dapat membantu Pembina dalam melaksanakan kegiatan pelatihan.

Dalam kurikulum HW belum secara eksplisit memuat muatan tentang bela negara, kendatipun dalam praktek kegiatannya telah menanamkan nilainilai yang terkait dengan bela negara.

Gerakan kepanduan HW merupakan salah satu organisasi otonom Muhammadiyah yang dibangkitkan kembali pada tahun 1999, karena peran Hizbul Wathan banyak terlihat pada sektor penanaman semangat cinta tanah air pada pemuda dan itu sudah dimulai sebelum Indonesia Merdeka. Implementasi ke depan tentang kepanduan Hizbul Wathan dalam memperbaiki kurikulum merupakan satu upaya melaksanakan atau mengimplementasikan kegiatan di sekolah Muhammadiyah, karena gerakan Hizbul Wathan merupakan upaya untuk membentuk kader yang ideologi praktis. Maksud ideologi praktis adalah kegiatan kader atau kumpulan gagasan yang berdaya guna yang efektif dan efisien.

Ekstrakurikuler gerakan kepanduan Hizbul Wathan sebenarnya sangat baik dilakukan peserta didik karena tujuannya bermanfaat, tetapi terkadang ada siswa yang malas untuk bergerak dan melanjutkan kegiatan ekstrakurikuler, peranan Pembina sangat besar pengaruhnya, harus ada program pembinaaan kegiatan ekstrakurikuler, melatih langsung peserta didik dalam kegiatan, mengevaluasi program, dan menyusun lapaoran kegiatan yang telah dilaksanakan.

\section{Saran}

Lembaga sekolah Muhammadiyah diharapkan selalu mengembangkan dan mensosialisasikan setiap perubahan kurikulum kepada peserta didik. Dalam kaitannya dengan pengembangan kompetensi bela negara, Pembina HW diharapkan dapat lebih meningkatkan partisipasinya dan ikut merealisasikan setiap perkembangan dan perubahan kurikulum, agar penerapan kurikulum dapat terlaksana dengan efektif. Kwarpus HW diharapkan agar selalu mengadakan evaluasi dan sosialisasi yang merata setiap terjadi perubahan kurikulum Siswa Muhammadiyah sebagai generasi penerus bangsa juga harus ditanamkan rasa tanggung jawab, rasa memiliki atau rasa cinta terhadap Negara. Nilai-nilai bela Negara seyogyanya dapat terus diintegrasikan dalam kegiatan di sekolah agar dapat mencetak generasi penerus bangsa.

Untuk membantu siswa lebih mudah menjiwai pendidikan bela Negara di sekolah membuat karya yang dapat memotivasi dan nilai-nilai bela Negara yang ingin diwujudkan sekolah

Ketertarikan Muhammadiyah dalam membina jajarannya harus didukung segala pihak, terutama kebangkitan aktivitas Gerakan kepanduan Hizbul Wathan. Intelijen yang dimiliki Hizbul Wathan dapat menjaga konsistensi dalam pelaksanaan beraktivitas.

\section{DAFTAR PUSTAKA}

Anderson, Alan H. dan Dennis Barker. 1996. Effective Enterprise and Change Management, (Blackwell Publisher Inc., Cambridge,)

Anderson, Terry Dubrin. 1998. Transforming Leadership, (St Lucie Press, Washington DC)

Affandi Ahmad. 2019. Pendidikan Kemuhammadiyahan, Jakarta: Majelis Pendidikan Dasar Dan Menengah Pimpinan Pusat Muhammadiya,

Ahmad Jauhari, Sofan Amri. 2011. Implementasi Pendidikan Karakter Dalam pembelajaran, Jakarta: Prestasi Pustaka,

Fanani Ahmad Fuad. 2018. Reimagining Muhammadiyah Islam berkemajuan Dalam pemikiran dan Gerakan, Yogjakarta: Suara Muhammadiyah 
Gerakan Kepanduan Hizbul Wathan, Peraturan Bina Karya Mandiri,Yogajakarta: Kedai HW

2018. Panduan Peserta Perkemahan Silaturrahim Nasional Milad Satu Abad Gerakan Kepanduan Hizbul Wathan, Jakarta:

2013. Sistem Pelatihan/Kursus Anggota Dewasa Dalam Kepanduan Hizbul Wathan.

2013. Pedoman Upacara Pembukaan Dan Penutupan Latihan Pandu Athfal, Pengenal, Penghela.

2013. Pedoman Administrasi Kwartir Pusat HW.

2018. Kurikulum Kepanduan Hizbul Wathan, Yogjakarta, Kwartir Pusat.

Majalah. 2018. Suara Muhammadiyah, Edisi 18.
- 2018.Sudirman dan Askar Perang sabil, Edisi 20.

Nashir, Haedar. 2019. Indonesia dan Keindonesaan, Yogjakarta: Suara Muhammadiyah. Omran, Ali, Kamel, 2005, Planning and Controllning, CAPSCU: Cairo Pidarta Made, 2013, Landasan Kependidika, Jakarta: Rineke Cipta.

Rosyid Muhadi Ahmad, dkk. 2019. Manifesto Cendekiawan Berfikir, Lamongan: Progresif Rais, Nurhasan, 2019, Kepanduan Hizbul Wathan \& Pendidikan Kepramukaan.

Robins S.P. 1991. Organizational Behavior: Concepts, Controversies and Aplication, (Prentice Hall International I., London nc,)

Suradika, Agus. 2000. Metode Penelitian Sosial. Jakarta: UMJ Press 